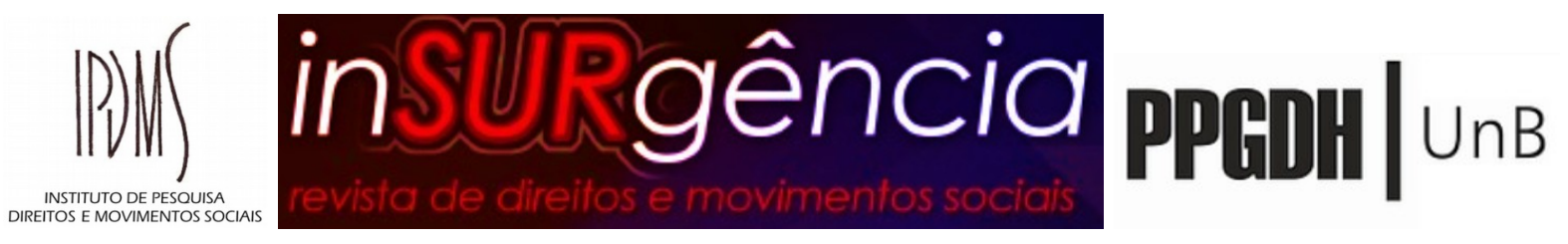

\title{
ACSELRAD, Henri. Cidade - Espaço público? A economia política do \\ consumismo nas e das cidades. Rev. UFMG, v. 20, n. 1, 2013. p. 234-247.
}

\author{
Marcelo Eibs Cafrune ${ }^{1}$ \\ Bruna Ramires Vieira ${ }^{2}$ \\ Emanuele Gebeluky Pinheiro ${ }^{3}$ \\ Marcela de Avellar Mascarello ${ }^{4}$ \\ Tâmara Circe Cerpa Moraes ${ }^{5}$ \\ Yago Freitas Blanco ${ }^{6}$
}

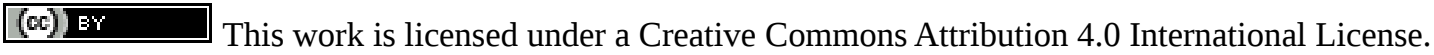

O artigo "Cidade - Espaço público? A economia política do consumismo nas e das cidades”, de Henri Acselrad, trata da apropriação privada dos espaços públicos urbanos por um conjunto de meios que operam nas cidades capitalistas contemporâneas.

Trata-se de um texto pequeno em extensão (13 páginas), mas denso e complexo, características da produção do autor. Publicado na Revista da UFMG, em 2013, dialoga com o contexto brasileiro de então, marcado por uma significativa mercantilização das cidades brasileiras.

Descrevendo os processos que ensejam a passagem do consumo para o consumismo, Acselrad destaca a construção social das necessidades; a valorização social do padrão de consumo; e a conversão da publicidade em mercadoria que invade e se apropria dos espaços públicos - e privados.

O autor retoma uma tradição crítica do urbanismo para atualizar a caracterização das cidades como lugares de consumismo e de consumismo de lugares. Em síntese, é possível dizer que com a emergência do planejamento estratégico e do empreendedorismo urbano, as

1 Doutor em Direito (UnB). Professor de Direito Urbanístico na Universidade Federal do Rio Grande (FURG). Email: marcelocafrune@furg.br.

2 Graduada em Relações Internacionais pela Universidade Federal de Santa Maria. Graduanda em Direito pela Universidade Federal do Rio Grande.

3 Graduanda em Direito pela Universidade Federal do Rio Grande.

4 Graduada em Oceanografia pela Universidade do Vale do Itajaí; Graduada em Direito pela Universidade Federal do Rio Grande-FURG. Técnica em Geoprocessamento pelo Instituto Federal do Rio Grande do SulIFRS.

5 Graduanda em Direito pela Universidade Federal do Rio Grande.

6 Graduando em Direito pela Universidade Federal do Rio Grande. 


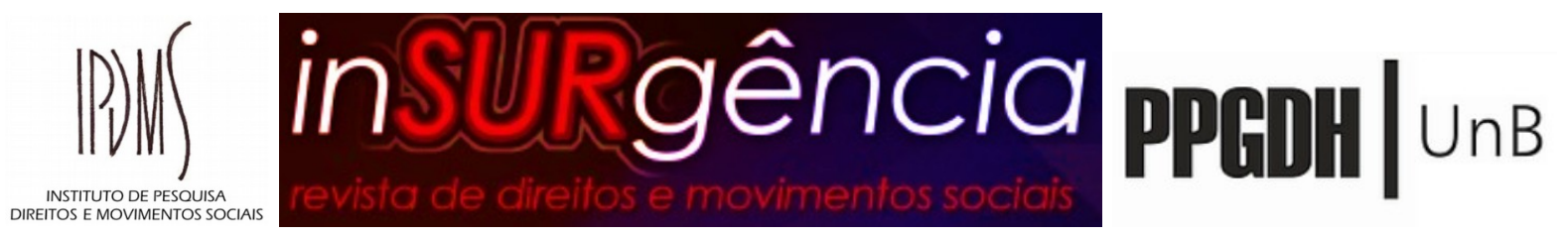

cidades passaram a ser vendidas por meio da combinação entre turismo, megaeventos, especulação imobiliária, competição por capitais etc.

Passa-se, assim, à exposição de alguns conceitos que, em razão da perspicácia analítica do autor, tornam o artigo relevante.

\section{a) Publicidade}

Para vender bens e lugares, operam três tipos de publicidade: microeconômica responsável por induzir as escolhas individuais; macroeconômica (ou institucional) responsável por reduzir a capacidade crítica e produzir consentimento social - especialmente por parte dos destituídos de poder - sobre definições políticas relativas à produção das cidades por poderosos atores econômicos ou políticos; e mesoeconômica ou mesopolítica.

A publicidade mesoeconômica (ou mesopolítica) é a promotora crucial do ideário sobre o espaço público e o que se pode nele fazer em nome do interesse público, a partir das lógicas privatizantes e mercantis. A publicidade mesopolítica é mais desenvolvida por Acselrad tamanho são os seus efeitos, configurando limitações de discursos e ideais políticos nos meios de comunicação que se apresenta, banindo de maneira desproporcional eventuais contrapontos. Destaca-se o papel central da mídia comercial para a visibilização/invisibilização dos processos de privatização do espaço público.

\section{b) Zonas de sacrifício e chantagem locacional}

Além de produzir mercadorias vendáveis, a atividade capitalista produz "nãomercadorias” invendáveis, por vezes chamadas de externalidades negativas, que exigem a criação de zonas de sacrifício, lugares que não se destinam ao consumo, mas sim ao depósito de resíduos resultantes da produção de mercadorias.

A definição da localização dessas zonas de sacrifício revela que a competitividade urbana se caracteriza, nos termos de David Harvey, por chantagem locacional, uma vez que as cidades competem entre si por investimentos ofertando lugares para receber, por consequência, poluição e gentrificação. É o ciclo econômico de desigualdade ambiental e urbana em nível global, regional e local. Frequentemente as zonas de sacrifício estão 


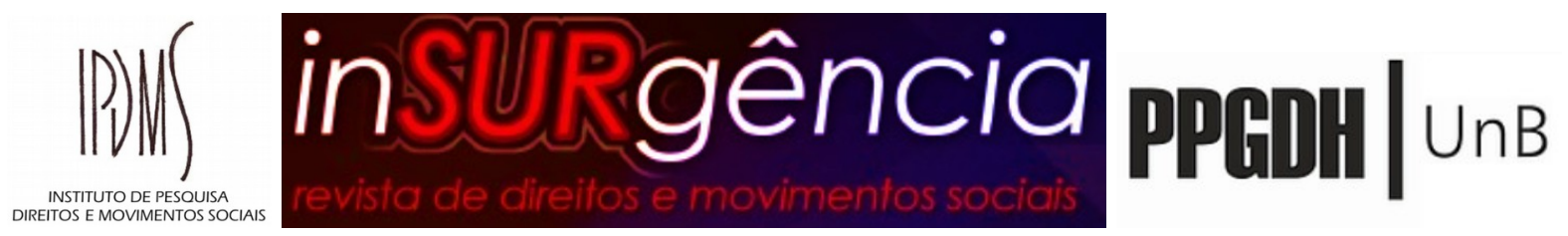

próximas dos grupos étnicos oprimidos e das populações pobres, em que a moradia, o trabalho e o ambiente são precários ou degradados.

\section{c) Movimentos de contestação do consumismo urbano}

Acselrad descreve que, em oposição à "cidade do consumo, da desigualdade e da discriminação opõem-se as forças da cidade não-mercantil, tais como movimentos de contestação do consumismo urbano” (p. 242), tais como grupos de sem-tetos que evidenciam falta de poder aquisitivo, mas experimentam os produtos de uma loja. Este exemplo antecipa o fenômeno dos rolezinhos que, no final do ano de 2013, mobilizaram por meio da internet milhares de jovens das periferias a se reunirem em shoppings centers do sudeste brasileiro para se divertir. Essas ações são apresentadas como uma prática para abrir a discussão e demonstrar a contradição dos lugares de consumismo.

As práticas de contestação dialogam, no presente, com a problemática dos aplicativos de entrega surgidos nos últimos anos, que reconhecidamente possuem regulação precária e despreocupada com a segurança, dignidade e bem-estar de seus trabalhadores, ao passo que rearticulam as temáticas de publicidade, tecnologia e mobilidade urbana. Destacam-se as mobilizações de julho de 2020, como a paralisação nacional “\#BrequeDosAPPs”.

\section{d) Mercantilização do espaço e não-lugares}

O autor enfatiza a contradição proveniente da aplicação da lógica mercantil aos espaços urbanos que prioriza o consumismo (das e nas cidades) acarretando a descaracterização destes enquanto espaços públicos. Esta organização das cidades em função da circulação de capital, cada vez mais acelerada, demanda a criação de espaços multifuncionais que facilitem as trocas mercantis, denominados por Marc Augé (1994) de não-lugares.

Não-lugares são espaços homogêneos, frutos da globalização, e transitórios, nos quais há grande circulação de pessoas, todavia não há criação de relações sociais (ou vínculos afetivos ou noção de coletividade), como shoppings, aeroportos, estacionamentos etc.

A configuração destes espaços repercute na autopercepção das pessoas, incentivando uma visão individualista e que, somado ao sistema econômico, faz com que os sujeitos se 


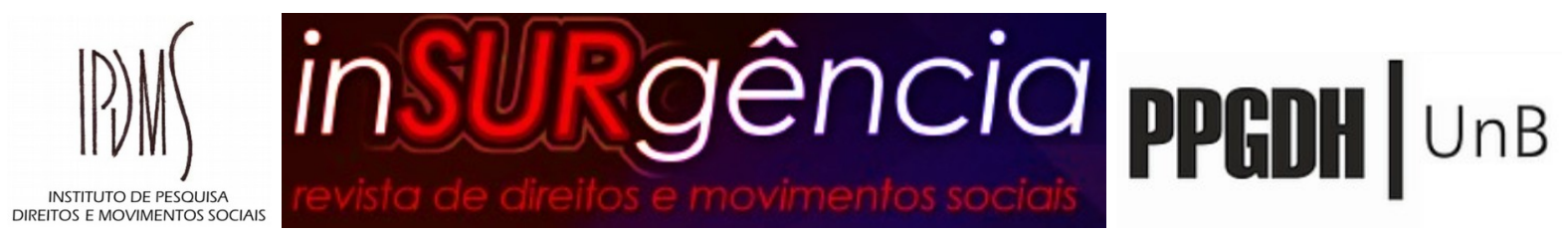

identifiquem majoritariamente enquanto consumidores e não como seres sociais. Nesta perspectiva, consumir é o principal objetivo do indivíduo substituindo “as múltiplas possibilidades de sua inserção no mundo da sociabilidade e da cultura” (p. 240). Configura-se, assim, o "homo neoliberalis de quem se espera preferir o shopping à cidade não mercantil” (p. 241) consolidando a ideologia que sustenta o sistema econômico.

A produção de localidades compreendidas como universais para sujeitos desiguais é excludente e culmina na descaracterização da cidade enquanto espaço público. Esta lógica está exemplificada no exemplo do planejamento de um estacionamento sobre o antigo Museu do Índio (ao lado do Maracanã, no Rio de Janeiro). Ou seja, priorizar a criação de um "nãolugar” em detrimento de um espaço que celebra a memória e identidade de um povo.

Em resposta a esta formatação espacial que limita o direito à cidade a quem possui capital para acessá-la, surgem movimentos que propõem a construção de locais multiculturais "reivindicando o reconhecimento de identidades específicas e de direitos a elas associados: eis o exemplo das experiências de cartografia social de indígenas nas cidades ou de reconhecimento de quilombos urbanos” (ACSELRAD, p. 244).

O artigo traz importantes aportes teóricos para descrever as cidades e pensar as possibilidades de reflexão no campo jurídico. Em geral, os conceitos sobre espaço público e cidade mobilizados no Direito são abstratos e formalistas, deixando de apreender a realidade que se pretende conhecer.

Sua relevância está em descrever adequadamente fenômenos que estão encobertos por percepções idealistas e normativas sobre a cidade. Em especial, a produção técnica realizada no campo jurídico (leis, decisões judiciais, pareceres etc.) detém-se na aparência das normas e dos documentos, olvidando os processos hegemônicos de produção de cidade e a relevância das vidas que nas cidades resistem.

Por consequência, operam-se inversões de toda ordem: ocupações tradicionais são removidas em defesa do direito de propriedade; práticas culturais são reprimidas em nome do meio ambiente; manifestações de rua são denunciadas por impedirem o livre trânsito de veículos. 


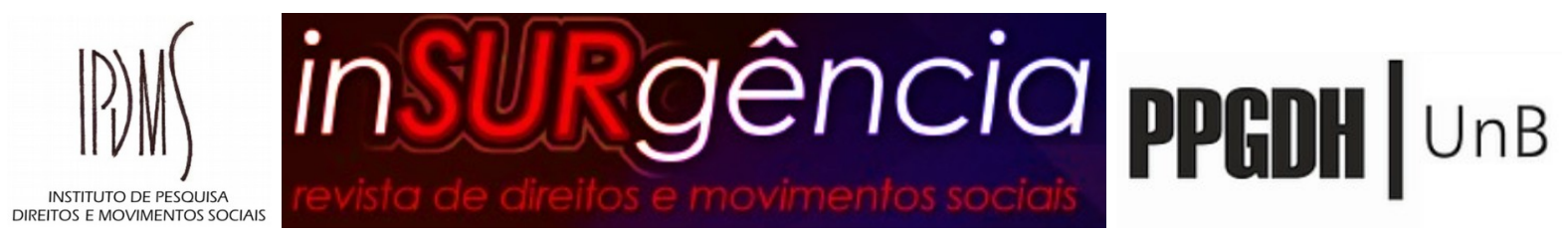

Assim, recomenda-se a leitura do artigo como forma de se pensar sobre a possibilidade de exercício de direitos nas cidades e o papel do Direito no processo de apropriação privada das cidades: “o que se está a pôr em jogo, pois, é a recuperação da cidade como espaço político, unindo lutas por reconhecimento e lutas por distribuição” (ACSELRAD, p. 246).

Para finalizar, é importante resgatar a trajetória de Henri Acselrad na construção do conceito de justiça ambiental para a realidade brasileira.

No ano de 2001, o autor ajudou a construir o Colóquio Internacional sobre Justiça Ambiental, Trabalho e Cidadania, realizado na Universidade Federal Fluminense, em Niterói, momento em que se criou a Rede Brasileira de Justiça Ambiental (RBJA) e se redigiu a sua declaração de lançamento.

Desde então, suas publicações são permeadas pela perspectiva da justiça ambiental, a qual pode ser definida como "o conjunto de princípios que asseguram que nenhum grupo de pessoas, sejam grupos étnicos, raciais ou de classe, suporte uma parcela desproporcional de degradação do espaço coletivo” (ACSELRAD; HERCULANO; PÁDUA, 2004, p. 09-10).

Nesse sentido, podemos afirmar que a cidade capitalista contemporânea é imersa em injustiças ambientais. É que essa cidade de consumo e esse consumismo da cidade, além de impor à população trabalhadora e pobre os maiores riscos e rejeitos da cidade mercadoria, também privatizam os espaços públicos e colocam ainda mais à margem as populações menos dotadas de recursos financeiros, políticos e informacionais.

Nessa perspectiva, o autor destaca no artigo a militância dos movimentos de justiça ambiental e de denúncia do racismo ambiental ao questionar as políticas fundiárias e ambientais em defesa do igual acesso à proteção ambiental, aos recursos ambientais e urbanos. Traz, também, a luta dos movimentos contra a ambientalização da exclusão, que denunciam o uso de argumentos ambientais para legitimar remoções de populações faveladas que não tiveram seu direito à moradia garantido.

É fundamental, portanto, a recuperação da cidade como espaço político para subverter a dinâmica mercantil.

\section{Referências}

ACSELRAD, H.; HERCULANO, S.; PÁDUA, J. A. A justiça ambiental e a dinâmica das lutas socioambientais no Brasil - uma introdução. In: ACSELRAD, H.; HERCULANO, S.; 


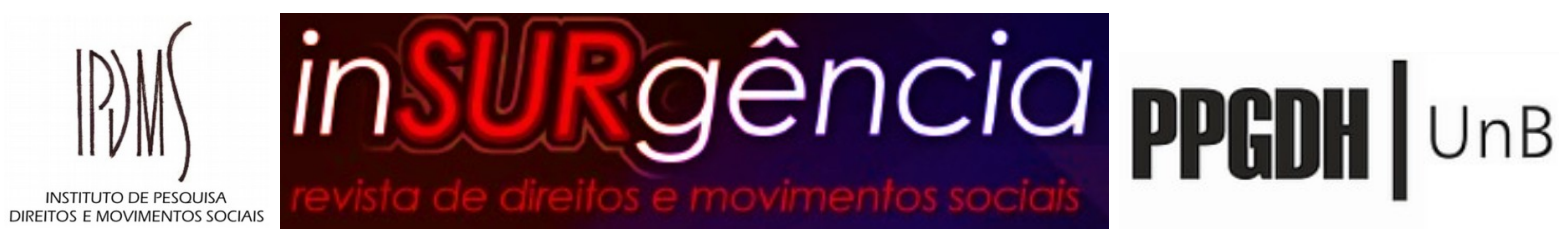

PÁDUA, J. A. Justiça Ambiental e Cidadania. Rio de Janeiro: Relume Dumará: Fundação Ford, 2004. p. 09-20.

AUGÉ, Marc. Não lugares: introdução a uma antropologia da supermodernidade. Campinas: Papirus, 1994.

Submetido em 14/07/2020.

Aprovado em 18/07/2020. 